УДК 378

DOI $10.21661 / \mathrm{r}-469003$

\title{
E.В. Свиридова
}

\section{АСИНХРОННАЯ ОРГАНИЗАЦИЯ УЧЕБНОГО ПРОЦЕССА КАК ОДИН ИЗ ПУТЕЙ УЛУЧШЕНИЯ ПРЕПОДАВАНИЯ ИНОСТРАННЫХ ЯЗЫКОВ В ВУЗЕ}

Аннотация: в статье рассматриваются особенности формирования компетенций на современном этапе развития вузовского образования. Уточняется роль современных учебных комплексов зарубежных издательств, мультимедийных и онлайн-ресурсов в создании благоприятных условий для коррекции индивидуальной траектории обучения.

Ключевые слова: асинхронная организачия учебного прочесса, преподавание иностранных языков в вузе, индивидуальная траектория обучения.

\section{E.V. Sviridova}

\section{ASYNCHRONOUS ORGANIZATION OF EDUCATIONAL PROCESS AS ONE OF THE WAYS OF IMPROVING THE TEACHING OF FOREIGN LANGUAGES IN HIGH SCHOOL}

Abstract: the article discusses on the formation of competence at the present stage of education development in high school. The role of the modern training systems of international publishers, multimedia and online resources in creating favorable conditions for the correction of individual learning paths are specified from different points of view.

Keywords: asynchronous organization of educational process, the teaching of foreign languages in high school, individual learning paths.

Подготовка компетентных, востребованных на рынке труда, специалистов всегда стояла во главе приоритетных задач российского образования. Особую остроту этого процесс приобрел в свете модернизации образования и глобализа- 
ции в мире. В условиях многоязычной социальной, экономической, политической, академической среды перед системой российского высшего образования стоит вопрос формирования и оценивания общекультурных, универсальных, общепрофессиональных и профессиональных компетенций, достигаемых обучающимися в высших учебных заведениях.

Задача формирования и оценивания достигнутых обучающимися компетенций актуальна для любой вузовской дисциплины. Субъектом применения могут выступать и отдельные вузы с подразделениями, и преподаватели, избирающие образовательные стратегии, и обучающиеся, определяющие для себя наиболее оптимальную траекторию обучения.

В настоящее время невозможно представить самостоятельную развитую личность, реализующую свой потенциал в профессиональной сфере без владения иностранным языком, то есть без сформированных способностей к письменной и устной коммуникации на иностранном языке, готовности работать в иноязычной среде, толерантно воспринимая социальные, этнические, конфессиональные и культурные различия.

Такие аспекты процесса модернизации как переход к системе многоуровневого образования, развитие мобильных образовательных программ и стандартов (Европейская Система Квалификаций), достижение академической мобильности, предполагают наличие альтернатив в образовательной сфере и заставляют обучающегося делать выбор, исходя из собственных возможностей и потребностей рынка труда [1]. В конечном итоге, данные мероприятия позволяют каждому обучающемуся достигать те компетенции, которые требуются «здесь и сейчас»».

Пути улучшения обучения иностранным языкам в вузе достаточно разнообразны. Среди них часто отмечают следующие:

- использование инновационных образовательных технологий;

- введение кредитно-модульной системы организации учебного процесса;

- компетентностно-ориентированное обучение;

- асинхронную организацию учебного процесса; 
- систему академического консультирования.

Асинхронная организация учебного процесса представляется наиболее новой формой. Для асинхронной организации учебного процесса используется также сочетание сетевых компьютерных технологий и мультимедийных курсов. Асинхронная организация позволяет проектировать индивидуальные траектории обучения «в удобное время и в удобном месте» с возможностью модификации учебного материала и технических решений. Это особенно важно, поскольку личная мотивация к изучению иностранных языков является определяющей для успешного достижения реальных образовательных целей.

Современные учебные комплексы, предлагаемые известными издательствами учебной литературы, такими как Cornelsen Verlag Berlin, Hueber Verlag, Klett Verlag, Langenscheidt Verlag и другими, содержат учебные материалы, отобранные экспертами для конкретных целевых групп и уровней владения иностранным языком, способны поддержать учебный процесс актуальными заданиями и позволяют достигать конкретных поставленных результатов [4-7].

В процессе самостоятельной работы с такими комплексами обучающиеся могут не только уверенно овладевать лексикой, грамматикой, фонетикой, правописанием иностранного языка, но и пытаться понять культуру и историю стран изучаемого языка, что необходимо для изучения экстралингвистических особенностей функционирования языка и его использования в процессе коммуникации с людьми. Представленный в занимательной форме учебный материал и игровые элементы в обучении способствуют запоминанию материала и обеспечивают успешный результат.

Успех в изучении иностранного языка, достижении обучающимися компетенций, зависит также от развития личной мотивации. Многочисленные мультимедиа, обладающие высоким интерактивным потенциалом, в особенности онлайн-ресурсы, способствуют этому развитию в большей степени. Возможность общения онлайн с другими обучающимися и преподавателем также обладает привлекательностью и создает благоприятные условия для коррекции индивидуальной траектории обучения в асинхронной организации учебного процесса. 
Современное изучение иностранных языков предполагает наряду с классическим обучением традиционным видам речевой деятельности чтению, письму, аудированию, говорению, также уверенное владение навыками работы с мультимедиа и многообразными учебными материалами в цифровой и аналоговой форме. Изучение иностранного языка с применением цифровых мультимедиа является особенно гибким, поскольку онлайн-ресурсы доступны в любое время, в любом месте и соответствуют разным стратегиям обучения. Такие интернетплатформы как Moodle также предлагают современный инструмент для изучения иностранных языков, для реализации индивидуальной траектории обучения в асинхронной организации учебного процесса.

Таким образом, вышеизложенное является основанием для заключения о том, что управление процессом формирования и оценивания достигаемых обучающимися общекультурных, универсальных, общепрофессиональных и профессиональных компетенций может осуществляться, в том числе, за счет внедрения асинхронной организации учебного процесса. Управление этим процессом возможно осуществить посредством структурных компонентов методических единиц обучения, возможности использования информации из разных источников, с различным техническим решением в их взаимодействии и взаимоотношении, которые взаимосодействуют на получение искомого результата с учетом использования современных образовательных технологий.

\section{Список литературы}

1. Бермус А.Г. Модернизация образования: философия, политика, культура: Научная монография / А.Г. Бермус.- М.: Канон+; РООИ «Реабилитация», 2008. - C. 343-344.

2. Кожевникова И.Г. Мобильные технологии и иноязычные интернет-ресурсы как фактор воздействия на формирование профессиональной мобильности при обучении иностранному языку студентов неязыковых вузов / И.Г. Кожевникова, Н.А. Иванова, Т.Ф. Голик // Современные проблемы науки и образования. - 2016. - №4. - С. 203. 
3. Свиридова Е.В. Применение современных программных продуктов для контроля уровня владения иностранным языком / Е.В. Свиридова // Materiały VII Międzynarodowej naukowi-praktycznej konferencji «Dynamika naukowych badań 2011. Volume 12. - Filologiczne nauki: Przemyśl. Nauka i studia, 2011. - S. 42-44.

4. [Электронный pecypc]. - Режим доступа: www.cornelsen.de

5. [Электронный ресурс]. - Режим доступа: www.klett.de

6. [Электронный ресурс]. - Режим доступа: www.langenscheidt.de

7. [Электронный ресурс]. - Режим доступа: www.heuber.de

\section{References}

1. Bermus A.G. Modernizatsiya obrazovaniya: filosofiya, politika, kul'tura: Nauchnaya monografiya [Modernization of education: philosophy, politics, culture]. Moskow, «Kanon+», ROOI «Reabilitatsiya» Publ., 2008, pp. 343-344. (In Russ.).

2. Kozhevnikova I.G., Ivanova N.A., Golik T.F. Mobil'nye tekhnologii i inoyazychnye internet-resursy kak faktor vozdejstviya na formirovanie professional'noj mobil'nosti pri obuchenii inostrannomu yazyku studentov neyazykovykh vuzov [Mobile technologies and foreign Internet resources as an influencing factor on occupational mobility formation when foreign language teaching in nonlinguistik higher education institutes]. Sovremennye problemy nauki i obrazovaniya. [The modern problems of science and education], 2016, no. 4. - p. 203. (In Russ., absrt. in Engl.).

3. Sviridova E.V. Primenenie sovremennykh programmnykh produktov dlya kontrolya urovnya vladeniya inostrannym yazykom [Application of the modern software products for monitoring of level of proficiency in a foreign language]. Materialy VII Miedzynarodowej naukowi-praktycznej konferencji "Dynamika naukowych badan - 2011" [ Proceedings of the Seventh International Scientific and Practical Conference "Dynamics of scientific research - 2011"]. Przemysl: Publ. Nauka i studia, 2011, no. 12 Filologiczne nauki, pp. 42-44. (In Russ.).

4. [Electronic resource]. - Access mode: www.cornelsen.de

5. [Electronic resource]. - Access mode: www.klett.de

6. [Electronic resource]. - Access mode: www.langenscheidt.de

7. [Electronic resource]. - Access mode: www.heuber.de 
Свиридова Елена Владимировна - канд. филол. наук, доцент кафедры иностранных языков Воронежского филиала ФГБОУ ВО «Российский экономический университет им. Г.В. Плеханова», Россия, Воронеж.

Sviridova Elena Vladimirovna - candidate of philological sciences, assistant professor of foreign languages, Voronezh branch of the Plekhanov Russian University of Economics, Russia, Voronezh. 